\title{
Molecular Taxonomy of a Phantom Midge Species (Chaoborus flavicans) in Korea
}

\author{
Haein An, Gila Jung, Chang-Bae Kim* \\ Department of Green Life Science, Sangmyung University, Seoul 110-743, Korea
}

\begin{abstract}
The larvae of Chaoborus are widely distributed in lakes, ponds, and reservoirs. These omnivorous Chaoborus larvae are crucial predators and play a role in structuring zooplankton communities, especially for small-sized prey. Larvae of Chaoborus are commonly known to produce predator-induced polyphenism in Daphnia sp. Nevertheless, their taxonomy and molecular phylogeny are very poorly understood. As a fundamental study for understanding the role of Chaoborus in predator-prey interactions in a freshwater ecosystem, the molecular identification and phylogenetic relationship of Chaoborus were analyzed in this study. A molecular comparison based on partial mitochondrial cytochrome oxidase I(COI) between species in Chaoborus was carried out for the identification of Chaoborus larvae collected from 2 localities in Korea. According to the results, the Chaoborus species examined here was identified as $C$. flavicans, which is a lake-dwelling species. Furthermore, partial mitochondrial genome including COI, COII, ATP6, ATP8, COIII, and ND3 were also newly sequenced from the species and concatenated 5 gene sequences excluding ATP8 with another 9 dipteran species were compared to examine phylogenetic relationships of $C$. flavicans. The results suggested that Chaoborus was more related to the Ceratopogonidae than to the Culicidae. Further analysis based on complete mitochondrial DNA sequences and nuclear gene sequences will provide a more robust validation of the phylogenetic relationships of Chaoborus within dipteran lineages.
\end{abstract}

Keywords: phantom midge, Chaoborus flavicans, molecular identification, phylogenetic relationship, Korea

\section{INTRODUCTION}

Chaoboridae, a family of Diptera, is commonly known as phantom midges. These are common midges with cosmopolitan distribution. Aquatic larvae of Chaoborus, a common genus of the family, are widely distributed in lakes, ponds, and reservoirs. Omnivorous Chaoborus larvae are crucial predators in structuring zooplankton communities, especially for the small-sized prey such as Daphnia, water flea. Larvae of Chaoborus are commonly known to produce predatorinduced polyphenism in Daphnia sp., which is a morphological defense for planktonic crustaceans by adaptive developmental plasticity (Tollrian and Dodson, 1999; Simon et al., 2011).

Despite the important ecological role of Chaoborus, their taxonomy and phylogenetic relationships remain unresolved. According to Dupuis et al. (2008), the monophyletic relationships of species in Chaoborus were highly questionable, and several cryptic species have been suggested. Especially, 2 cryptic species in Chaoborus flavicans were indicated according to its habitats, morphological characters, and mitochondrial cytochrome oxidase I (COI) sequences. Based on the morphological characters and $18 \mathrm{~S}$ and $5.8 \mathrm{~S}$ ribosomal DNA sequences, it has been suggested that Chaoboridae is more closely related to the Culicidae than Ceratopogonidae in the culicomorphan Diptera (Miller et al., 1997; Sæther, 2000). In other molecular phylogenetic studies (Friedrich and Tautz, 1997; Cameron et al., 2007) conducted with the purpose of testing the traditional hypotheses on relationships between families of the dipterans, the species in Chaoboridae were not included in analyses.

Species in Chaoboridae have never known to inhabit Korea until recently, and even the family name did not appear in the Checklist of Insects from Korea (The Entomological Society of Korea and Korean Society of Applied Entomology, 1994). Recently, Jeong (2010) reported Chaoborus flavicans from

\footnotetext{
(c) This is an Open Access article distributed under the terms of the Creative Commons Attribution Non-Commercial License (http://creativecommons.org/ licenses/by-nc/3.0/) which permits unrestricted non-commercial use, distribution, and reproduction in any medium, provided the original work is properly cited. pISSN 2234-6953
}

*To whom correspondence should be addressed

Tel: 82-2-2287-5288, Fax: 82-2-2287-0070

E-mail: evodevo@smu.ac.kr 
the Sangchun reservoir in Gyeonggi-do, based mainly on mandible morphology and partial COI sequences. Therefore, their taxonomy and distribution are very poorly understood in Korea. In this study, molecular identification and phylogenetic relationships of Chaoborus were analyzed as a fundamental study for understanding the role of Chaoborus in predator-prey interactions in a freshwater ecosystem.

\section{MATERIALS AND METHODS}

\section{Collection and DNA extraction}

Larvae of Chaoborus were collected by a Bongo net of 60 $\mathrm{cm}$ mouth diameter and $300 \mu \mathrm{m}$ mesh size in the Sangchun reservoir in Gyeonggi-do and the Ildae reservoir in Jeollanam-do. Collected specimens were preserved in $100 \%$ ethyl alcohol before storing at $-20^{\circ} \mathrm{C}$ until DNA extraction. DNA was extracted by using an AccuPrep Genomic DNA extraction kit (Bioneer, Korea).

\section{Molecular identification}

For molecular identification, the partial mitochondrial COI region was PCR amplified by employing primers COIF and COIR (Table 1 ), in a total volume of $20 \mu \mathrm{L}$ consisting of $2 \times$ TOPsimple DyeMIX-Tenuto (Enzynomics, Korea), 100 ng template DNA, 2 pmol dNTPs, and 5 pmol of each primer. The PCR protocol consisted of initial denaturation at $94^{\circ} \mathrm{C}$ for $3 \mathrm{~min}, 35 \mathrm{cycles}$ of $94^{\circ} \mathrm{C}$ for $30 \mathrm{sec}, 45^{\circ} \mathrm{C}$ for $30 \mathrm{sec}$, and $72^{\circ} \mathrm{C}$ for $1 \mathrm{~min}$, followed by final extension, $72^{\circ} \mathrm{C}$ for $7 \mathrm{~min}$. PCR products were purified using the AccuPrep PCR Purification kit (Bioneer). Sequencing reactions were performed using the BigDye Terminators kit 3.1, and run on an ABI 3730 Automated Sequencer (Applied Biosystems, USA). Using Blastn search, COI sequences similar to the present sequences were retrieved (Table 2) and multiply aligned by CLUSTAL W (Larkin et al., 2007) in the Geneious Pro 5.4.6 program (Biomatters, New Zealand). Neighbor-Joining tree based on the Kimura two-parameter model was inferred by PAUP4.0b10* (Swofford, 2003). Tree robustness was examined by bootstrap analysis using 1,000 replicates.

\section{PCR amplification and DNA sequencing of partial mitochondrial genome}

For phylogenetic analysis, more than $4 \mathrm{~kb}$ DNA including mitochondrial coding genes COI, COII, ATP6, ATP8, and COIII was amplified from a individual collected from the Sangchun reservoir by using PCR primers, CI-J-1632 and C3-J-5460 (Table 1) by using the same PCR reaction composition for the molecular identification and the following PCR protocol: $92^{\circ} \mathrm{C}$ for $2 \mathrm{~min}$ and 40 cycles of $92^{\circ} \mathrm{C}$ for $30 \mathrm{sec}$, $45^{\circ} \mathrm{C}$ for $30 \mathrm{sec}, 68^{\circ} \mathrm{C}$ for $12 \mathrm{~min}$, followed by final extension, $68^{\circ} \mathrm{C}$ for $20 \mathrm{~min}$. For PCR amplification of genes inside the long PCR fragment, several internal PCR primers were designed (Table 1) and separate PCR reactions were executed using these primers. ND3 was amplified by the PCR primers, C3-I-F and N4-I-R. PCR products were purified using the AccuPrep PCR Purification kit. Sequencing reactions were performed using BigDye Terminators kit 3.1, and run on an ABI 3730 Automated Sequencer.

\section{Phylogenetic relationship}

For comparison, another 9 dipteran species and Locusta migratoria were used as an outgroup from which complete mitochondrial DNA sequences are known were retrieved from the GenBank (Table 3). Based on the conserved (C)/variable (V) site ratios and percentage of gaps and invariable sites as an estimation of reliability of alignment (Lee et al., 2006), ATP8 did not show reliability (data not shown). ATP8 gene was commonly excluded from phylogenetic studies using mitochondrial genome. Except ATP8 gene 5 genes were used for further phylogenetic analyses. After translating the DNA sequences, reading frames of DNA sequences were confirmed by concatenating and aligning 5 mitochondrial coding genes by using CLUSTAL W in the Geneious Pro 5.4.6 pro-

Table 1. List of PCR primers used in this study

\begin{tabular}{llll}
\hline Target gene & \multicolumn{1}{c}{ Primer } & \multicolumn{1}{c}{ Sequence $\left(5^{\prime} \rightarrow 3^{\prime}\right)$} & \multicolumn{1}{c}{ References } \\
\hline COI-COIII & CI-J-1632 & TGATCAATTTATAAT & Kambhampati and Smith, 1995 \\
& C3-J-5460 & TCAACAAAGTGTCAGTATCA & Cameron et al., 2007 \\
COI & COIF & GAAGCTAAAATCA et al., 2008 \\
& COIR & CTTATTTACTTCAGCAATAATTA & Dupuis et al., 2008 \\
COI & C1F & ACCTCCTTCTTGACCCTGC & In this study \\
& C1R & GGACTACTCCTGTTAATCCTCC & In this study \\
COII & C2F & CTTAGGGTTAGCTGGAATGCC & In this study \\
& C2R & GGAAGAACAATACGATTATCTACATCT & In this study \\
COI-COIII & C3IR & AGGGGTCATGGGCTATAATCTACT & In this study \\
COIII-ND3 & C3-I-F & GGCATACGAATATATAGAAGCATC & In this study \\
& N4-I-R & TCAACCTGAGCGTTACAGGCTGGG & In this study \\
\hline
\end{tabular}

CO, cytochrome oxidase. 
gram.

For reconstucting the phylogenetic trees based on 5 mitochondrial coding genes from dipteran species, a substitution model was chosen using MrModeltest version 2.02 (Nylander,

Table 2. List of COI nucleotide sequences of Chaoborus species using for phylogenetic analysis

\begin{tabular}{|c|c|c|}
\hline Species & Location & Accession no. \\
\hline C. flavicans & Turkey & DQ146242 \\
\hline C. flavicans & Turkey & DQ146264 \\
\hline C. flavicans & Sweden & DQ146266 \\
\hline C. flavicans & Sweden & DQ146280 \\
\hline C. flavicans & Sweden & DQ146249 \\
\hline C. flavicans & Sweden & DQ146253 \\
\hline C. flavicans & Indiana & DQ146238 \\
\hline C. flavicans & Indiana & DQ146243 \\
\hline C. flavicans & Newyork & DQ146297 \\
\hline C. flavicans & Newyork & DQ146296 \\
\hline C. cf. flavicans & Alaska & DQ146230 \\
\hline C. cf. flavicans & Japan & DQ146274 \\
\hline C. cf. flavicans & Alaska & DQ146233 \\
\hline C. cf. flavicans & Alaska & DQ146239 \\
\hline C. cf. flavicans & Alberta & DQ146255 \\
\hline C. cf. flavicans & Alberta & DQ146295 \\
\hline C. cf. flavicans & Japan & DQ146284 \\
\hline C. cf. flavicans & Japan & DQ146300 \\
\hline C. cf. flavicans & Indiana & DQ146271 \\
\hline C. cf. flavicans & Indiana & DQ146301 \\
\hline C. albatus & Unknown & AJ427614 \\
\hline C. americanus & Alberta & DQ146279 \\
\hline C. americanus & British Columbia & DQ146273 \\
\hline C. astictopus & Unknown & AJ427613 \\
\hline C. cooki & Unknown & AJ427616 \\
\hline C. crystallinus & Finland & DQ146256 \\
\hline C. crystallinus & Sweden & DQ146305 \\
\hline C. obscuripes & Unknown & AJ427615 \\
\hline C. punctipennis & Newyork & DQ146236 \\
\hline C. punctipennis & Indiana & DQ146283 \\
\hline C. punctipennis & Arkansas & DQ146267 \\
\hline C. pallidus & Unknown & AJ427622 \\
\hline C. trivitattus & Unknown & AJ427620 \\
\hline Anophele quadrimaculatus & Unknown & NC 000875 \\
\hline A. gambiae & Unknown & NC 002084 \\
\hline
\end{tabular}

COI, cytochrome oxidase I.
2004) under Akaike's information criterion. The GTR+I+G model was used to generate a Bayesian inference and a maximum likelihood (ML) tree. The Bayesian tree was obtained with MRBAYES version 3.1.2 (Ronquist and Huelsenbeck, 2003) with default options for the prior distribution in the Bayesian inferences. Metropolis-coupled Markov chain Monte Carlo (MCMCMC) analyses were run with one cold chain and 3 heated chains for 1,000,000 generations from 5 mitochondrial coding genes, and sampled every 100 generations. Two independent MCMCMC runs were performed and 2,500 trees were discarded as burn-in from the 5 mitochondrial coding genes. The final trees near the optimum likelihood score were retained using the appropriate burn-in criterion. Trees from 5 mitochondrial coding genes were retained and used for calculation of posterior probabilities. A ML tree was constructed using PAUP4.0b10* by heuristic search with a truncated balanced realization algorithm. The tree stability was examined by bootstrap analysis with 100 replicates.

The sequence alignment is available upon request from the corresponding author.

\section{RESULTS AND DISCUSSION}

\section{Molecular identification}

For molecular identification, 6 individual specimens from Sangchun reservoir in Gyeonggi-do and 3 from Ildae reservoir in Jeollanam-do were used for generation of COI barcodes. In addition, 2 specimens from the National Institute for Environmental Studies of Japan were also examined for comparison. Sequences were deposited in GenBank (accession nos: JQ277990-JQ278000). Based on the sequence comparison of the COI gene, the specimens from the 2 Korean reservoirs were almost identical $(0.06 \%)$, while the specimens from Korean and Japanese populations showed $18 \%$ differences in genetic distance which are close to values for putative cryptic species suggested by Dupuis et al. (2008). According to the

Table 3. List of species compared with Chaoborus for phylogeny reconstruction

\begin{tabular}{|c|c|c|c|c|}
\hline Order & Suborder & Family & Species & Accession no. \\
\hline \multirow[t]{9}{*}{ Diptera } & Brachycera & Calliphoridae & Cochliomyia hominivorax & NC_002660 \\
\hline & & Drosophilidae & Drosophila sechellia & NC_005780 \\
\hline & & Drosophilidae & Drosophila simulans & NC_005781 \\
\hline & & Muscidae & Haematobia irritans irritans & NC_007102 \\
\hline & Nematocera & Ceratopogonidae & Culicoides arakawae & NC_009809 \\
\hline & & Culicidae & Anopheles darlingi & NC_014275 \\
\hline & & Culicidae & Anopheles gambiae & NC_002084 \\
\hline & & Culicidae & Aedes albopictus & NC_006817 \\
\hline & & Culicidae & Culex pipiens pipiens & NC_015079 \\
\hline Orthoptera & Caelifera & Acrididae & Locusta migratoria & NC_001712 \\
\hline
\end{tabular}




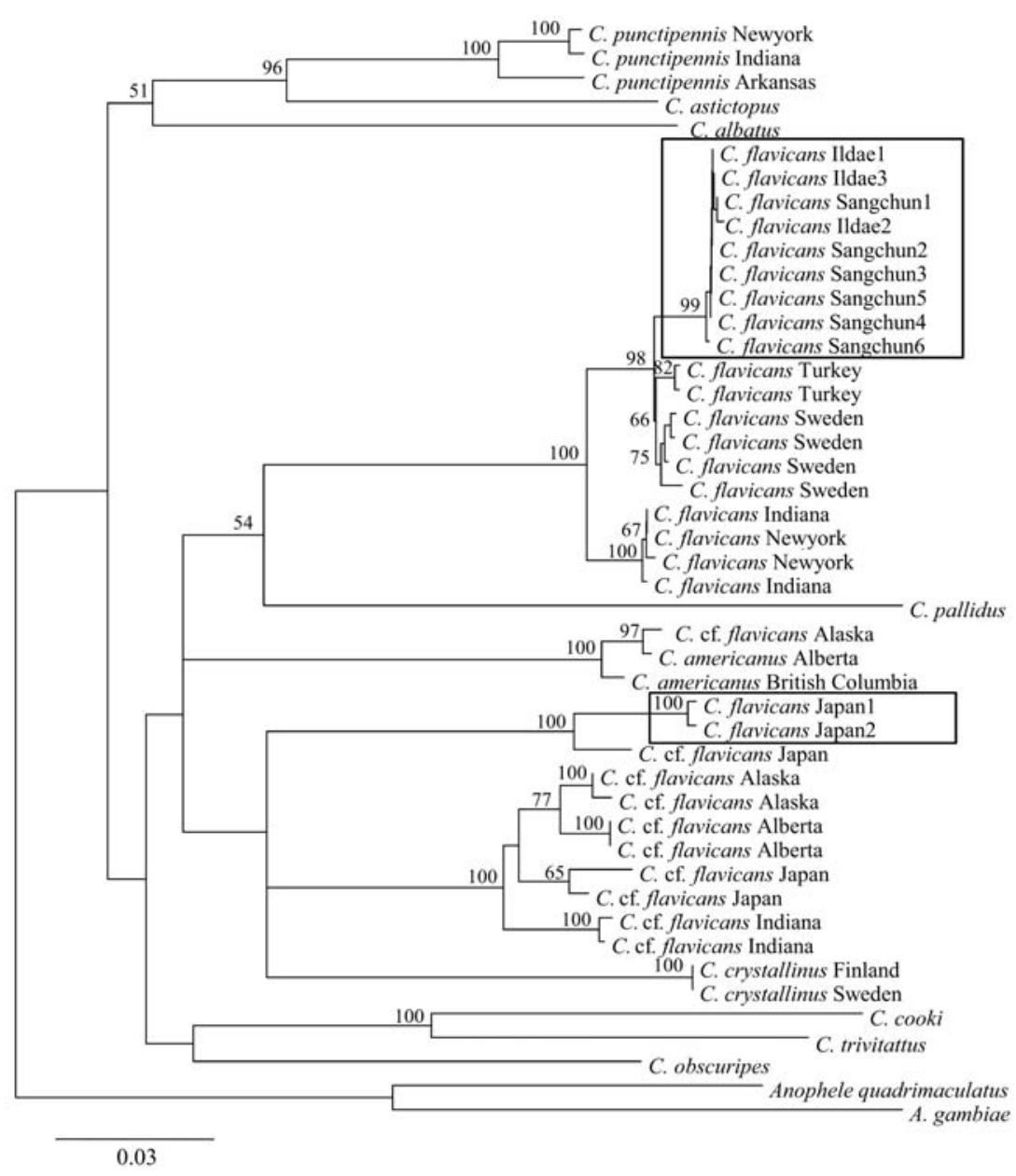

Fig. 1. Neighbor-joining tree for Chaoborus species based on partial mitochondrial cytochrome oxidase I (COI) gene sequences. Values above the branches indicate $>50 \%$ bootstrap support. Boxes include specimens examined in the study.

neighbor-joining tree (Fig. 1), all the specimens examined in this study belonged to the Chaoborus flavicans group. Two subgroups were recognized in the $C$. flavicans group 2. Each of the Korean and Japanese populations was assigned to a separate subgroup. The 2 subgroups corresponded to the 2 cryptic species suggested by Dupuis et al. (2008). According to Dupuis et al. (2008), 2 cryptic species have been recognized by having different habitats (lake-dwelling and pond-dwelling) and morphological characteristics, especially the mandible. Korean populations were included in the lake-dwelling group and were well discriminated from the pond-dwelling group, including the Japanese population. Populations from the Palearctic and Nearctic were well recognized in the lake-dwelling group, as indicated by Dupuis et al. (2008).

\section{Organization of protein coding genes of $\boldsymbol{C}$. flavicans}

Sequences of the partial mitochondrial genome were deposited in GenBank (accession no: JQ235548). The partial mito- chondrial genome of $C$. flavicans including COI, tRNA-Leu, COII, tRNA-Lys, tRNA-Asp, ATP8, ATP6, COIII, tRNAGly, ND3, tRNA-Ala. was 4446 bp in length (Table 4). The overall AT content for six coding genes was $70.1 \%$ ( $\mathrm{T}=39.0$ $\%, \mathrm{C}=17.7 \%, \mathrm{~A}=31.1 \%, \mathrm{G}=12.3 \%$ ) similar to that of dipteran species.

The order of protein coding genes and tRNA was identical to that reported from many of insect species. The initiation and termination codons of the genes examined here were identified using the open reading frame finder and by comparison with mitochondrial gene sequences of other dipteran species. ATG and ATT were used as initiation codons (Table 4). In case of COI the initiation codon could not found because of the truncation of start region of the gene. The usual TAA termination codon found for all genes examined.

The codon usage of $C$. flavicans for six mitochondrial protein coding genes and the relative synonymous codon usage values are given in Table 5. Most of values differed from the 
Table 4. Annotation and gene organization of Chaoborus flavicans partial mitochondrial genome

\begin{tabular}{|c|c|c|c|c|c|c|c|}
\hline Gene & Direction & Position & $\begin{array}{l}\text { Overlapping } \\
\text { region }\end{array}$ & $\begin{array}{l}\text { Non-coding } \\
\text { region }\end{array}$ & Size & Initiation & Termination \\
\hline CO I & $\mathrm{F}$ & $1-1381$ & & 12 & 1381 & & TAA \\
\hline CO II & $\mathrm{F}$ & $1470-2153$ & & 2 & 684 & ATG (Met) & TAA \\
\hline tRNA-Lys & $\mathrm{F}$ & $2156-2226$ & & 18 & 71 & & \\
\hline tRNA-Asp & $\mathrm{F}$ & $2245-2312$ & & & 68 & & \\
\hline ATP6 & $\mathrm{F}$ & $2468-3136$ & & 22 & 669 & ATG (Met) & TAA \\
\hline CO III & $\mathrm{F}$ & $3159-3947$ & & 4 & 789 & ATG (Met) & TAA \\
\hline tRNA-Gly & $\mathrm{F}$ & $3952-4014$ & & & 63 & & \\
\hline ND3 & $\mathrm{F}$ & $4015-4368$ & & 9 & 354 & ATT (Ile) & TAA \\
\hline tRNA-Ala & $\mathrm{F}$ & $4378-4446$ & & & 69 & & \\
\hline
\end{tabular}

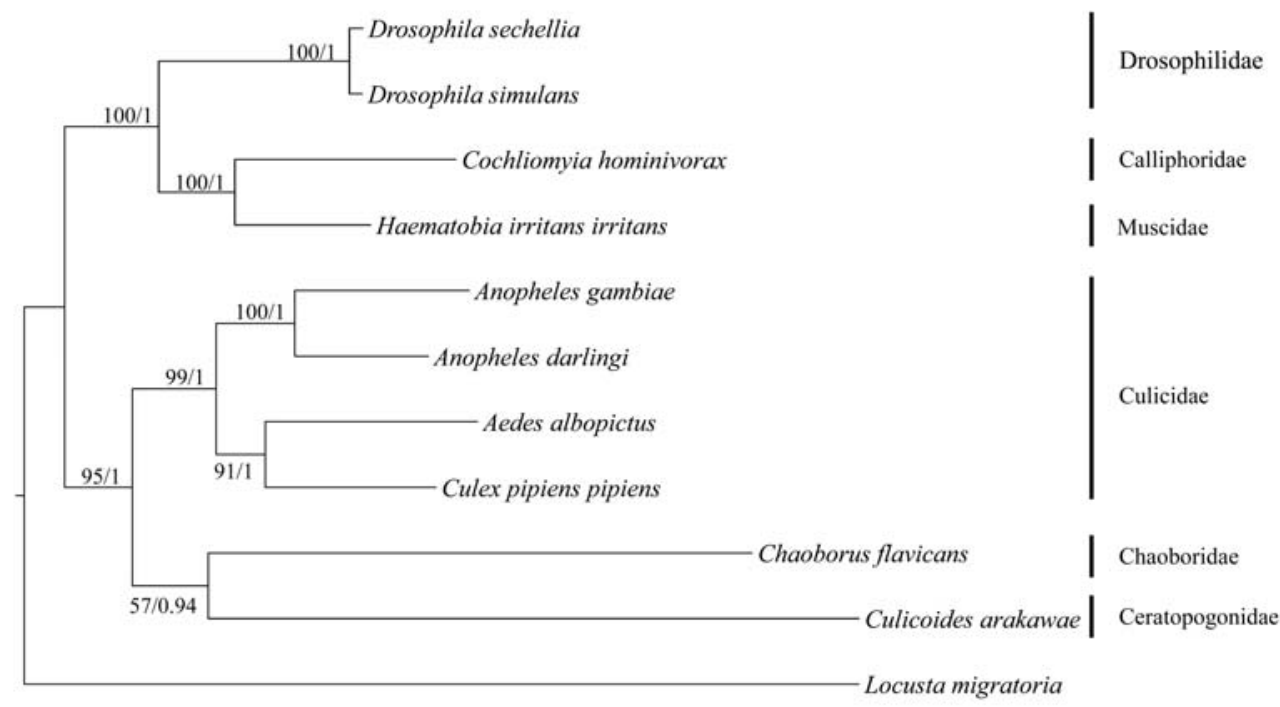

0.05

Fig. 2. Maximum likelihood (ML) tree for the selected dipteran species based on $3,840 \mathrm{bp}$ of five concatenated mitochondrial gene sequences. Values above and below the branches indicate ML bootstrap values and BI posterior probabilities, respectively.

equilibrium frequency and the use of synonymous codons was distorted. CUG (Leu), UCG (Ser), UAG (Termination), AAG (Lys), UGG (Trp), AGG (Ser) were not used in C. flavicans. Since mtDNA of insects show a high bias against $G$ and $\mathrm{C}$, this could explain the lack of these codons.

\section{Phylogenetic relationship}

The topology of resulting phylogeny based on ML and Bayesian interferences analyses recognized two clusters of the Diptera consisting of Brachycera and Nematocera with high boostrap supports. In the Nematocera, Chaoboridae was more closely related to Ceratopogonidae than to Culicidae in both analyses employed (Fig. 2). However, the present phylogeny suggested different relationships between families in Nematocera from previous analyses (Miller et al., 1997;
Sæther, 2000). These prior studies suggested that Ceratopogonidae was diverged early and Chaoboridae and Culicidae were more related. In this study, Ceratopogonidae and Chaoboridae were more related to each other, however, this relationship received little statistical support.

In this study, Chaoborus species from 2 reservoirs in Korea were identified as Chaoborus flavicans by mitochondrial COI gene sequences. Phylogenetic trees based on 5 mitochondrial coding genes by ML and Bayesian inferences showed Chaoborus was more closely related to the Ceratopogonidae than to Culicidae, however, this relationship received little statistical support. Therefore, further analyses based on complete mitochondrial DNA sequences and nuclear gene sequences are needed for a more robust validation of the phylogenetic relationship of Chaoborus within dipteran lineages. 
Table 5. Chaoborus flavicans codon usage of six protein coding region of partial mitochondrial genome

\begin{tabular}{|c|c|c|c|c|c|c|c|}
\hline Codon (aa) & $\mathrm{n}(\mathrm{RSCU})$ & Codon & $\mathrm{n}(\mathrm{RSCU})$ & Codon & $\mathrm{n}(\mathrm{RSCU})$ & Codon & $n(R S C U)$ \\
\hline UUU (F) & $93(1.54)$ & UCU (S) & 39 (2.79) & UAU (Y) & $26(1.16)$ & UGU (C) & $5(1.67)$ \\
\hline $\operatorname{UUC}(\mathrm{F})$ & $28(0.46)$ & $\operatorname{UCC}(\mathrm{S})$ & $10(0.71)$ & UAC (Y) & $19(0.84)$ & UGC (C) & $1(0.33)$ \\
\hline UUA (L) & $101(3.39)$ & UCA (S) & $32(2.29)$ & UAA $(*)$ & $6(2)$ & UGA (W) & $43(2)$ \\
\hline UUG (L) & $7(0.23)$ & UCG (S) & $0(0)$ & UAG $(*)$ & $0(0)$ & UGG (W) & $0(0)$ \\
\hline CUU (L) & $42(1.41)$ & $\operatorname{CCU}(P)$ & $33(2.06)$ & $\mathrm{CAU}(\mathrm{H})$ & $36(1.71)$ & CGU (R) & $7(1.17)$ \\
\hline CUC (L) & $3(0.1)$ & $\mathrm{CCC}(\mathrm{P})$ & $16(1)$ & $\mathrm{CAC}(\mathrm{H})$ & $6(0.29)$ & CGC (R) & $1(0.17)$ \\
\hline CUA (L) & $26(0.87)$ & $\mathrm{CCA}(\mathrm{P})$ & $13(0.81)$ & CAA (Q) & $29(1.87)$ & CGA (R) & $14(2.33)$ \\
\hline CUG (L) & $0(0)$ & CCG $(P)$ & $2(0.13)$ & CAG (Q) & $2(0.13)$ & CGG (R) & $2(0.33)$ \\
\hline AUU (I) & $126(1.7)$ & $\operatorname{ACU}(\mathrm{T})$ & $39(1.7)$ & AAU $(N)$ & $45(1.43)$ & AGU (S) & $9(0.64)$ \\
\hline $\operatorname{AUC}(\mathrm{I})$ & $22(0.3)$ & $\mathrm{ACC}(\mathrm{T})$ & $17(0.74)$ & $\mathrm{AAC}(\mathrm{N})$ & $18(0.57)$ & $A G C(S)$ & $2(0.14)$ \\
\hline AUA (M) & $76(1.85)$ & $A C A(T)$ & $35(1.52)$ & $\mathrm{AAA}(\mathrm{K})$ & $21(2)$ & AGA (S) & $20(1.43)$ \\
\hline AUG (M) & $6(0.15)$ & $\mathrm{ACG}(\mathrm{T})$ & $1(0.04)$ & AAG $(K)$ & $0(0)$ & AGG (S) & $0(0)$ \\
\hline GUU (V) & $21(1.4)$ & GCU (A) & $26(1.53)$ & GAU (D) & $18(1.2)$ & GGU (G) & $7(0.35)$ \\
\hline GUC (V) & $5(0.33)$ & GCC (A) & $14(0.82)$ & GAC (D) & $12(0.8)$ & GGC (G) & $1(0.05)$ \\
\hline GUA (V) & $32(2.13)$ & $\mathrm{GCA}(\mathrm{A})$ & $26(1.53)$ & GAA (E) & $28(1.87)$ & GGA (G) & $51(2.58)$ \\
\hline GUG (V) & $2(0.13)$ & $\operatorname{GCG}(A)$ & $2(0.12)$ & GAG (E) & $2(0.13)$ & GGG (G) & $20(1.01)$ \\
\hline
\end{tabular}

A total of 1346 codons were analyzed.

$\mathrm{RSCU}$, relative synonymous codon usage; $n$, frequency of each codon.

*Termination codons.

\section{ACKNOWLEDGMENTS}

This work was supported by the National Research Foundation of Korea (NRF) grant funded by the Korea government (MEST) (No. 2009-0080737). We thank Dr. Shigeto Oda, the National Institute for Environmental Studies of Japan for sending us Japanese specimens.

\section{REFERENCES}

Cameron SL, Lambkin CL, Barker SC, Whiting MF, 2007. A mitochondrial genome phylogeny of Diptera: whole genome sequence data accurately resolve relationships over broad timescales with high precision. Systematic Entomology, 32: 40-59.

Dupuis DD, Svensson JE, Taylor DJ, 2008. The cryptic origins of environment-indicating phantom midges (Chaoborus). Limnology and Oceanography, 53:236-243.

Friedrich M, Tautz D, 1997. Evolution and phylogeny of the Diptera: a molecular phylogenetic analysis using $28 \mathrm{~S}$ rDNA sequences. Systematic Biology, 46:674-698.

Jeong GR, 2010. Seasonal and diel abundance and feeding patterns of Chaoborus flavicans in Sang-Chun reservoir. MS thesis, Ajou University, Suwon, Korea, pp. 1-44.

Kambhampati S, Smith PT, 1995. PCR primers for the amplification of four insect mitochondrial gene fragments. Insect Molecular Biology, 4:233-236.

Larkin MA, Blackshields G, Brown NP, Chenna R, McGettigan PA, McWilliam H, Valentin F, Wallace IM, Wilm A, Lopez R, Thompson JD, Gibson TJ, Higgins DG, 2007. Clustal W and Clustal X version 2.0. Bioinformatics, 23:2947-2948.
Lee ES, Shin KS, Kim MS, Park H, Cho S, Kim CB, 2006. The mitochondrial genome of the smaller tea tortrix Adoxophyes honmai (Lepidoptera: Tortricidae). Gene, 373:52-57.

Miller BR, Crabtree MB, Savage HM, 1997. Phylogenetic relationships of the Culicomorpha inferred from $18 \mathrm{~S}$ and $5.8 \mathrm{~S}$ ribosomal DNA sequences (Diptera: Nematocera). Insect Molecular Biology, 6:105-114.

Nylander JAA, 2004. MrModeltest v2. Program distributed by the author. Evolutionary Biology Centre, Uppsala University, Uppsala.

Ronquist F, Huelsenbeck JP, 2003. MrBayes 3: Bayesian phylogenetic inference under mixed models. Bioinformatics, 19: $1572-1574$.

Sæther OA, 2000. Phylogeny of Culicomorpha (Diptera). Systematic Entomology, 25:223-234.

Simon JC, Pfrender ME, Tollrian R, Tagu D, Colbourne JK, 2011. Genomics of environmentally induced phenotypes in 2 extremely plastic arthropods. Journal of Heredity, 102: 512-525.

Swofford, DL, 2003. PAUP*: Phylogenetic Analysis Using Parsimony (*and other methods). Sinauer Associates, Sunderland, MA.

The Entomological Society of Korea and Korean Society of Applied Entomology, 1994. Checklist of insects from Korea. Konkuk University Press, Seoul, pp. 1-744.

Tollrian R, Dodson SI, 1999. Inducible defenses in Cladocera: constraints, costs, and multipredator environments. In: The ecology and evolution of inducible defenses (Eds., Tollrian R, Harvell CD). Princeton University Press, Princeton, NJ, pp. 177-202.

Received October 10, 2011 Revised December 21, 2011 Accepted December 26, 2011 